\title{
Renal leiomyoma: Case report and literature review
}

\author{
Eugenio Brunocilla, MD, PhD;* Cristian Vincenzo Pultrone, MD;* Riccardo Schiavina, MD, PhD;* \\ Valerio Vagnoni, MD;* Giacoma Caprara, MD; Giuseppe Martorana, MD, PhD*
}

*Department of Urology, University of Bologna, S. Orsola-Malpighi Hospital, Bologna, Italy; †Department of Haematology Oncology and Laboratory Medicine, "F. Addarii" Institute of Oncology, University of Bologna, S. Orsola-Malpighi Hospital, Bologna, Italy

Cite as: Can Urol Assoc J 2012;6(2):e87-90. http://dx.doi.org/10.5489/cuaj.11159

\section{Abstract}

Renal leiomyomas are rare benign tumours of the kidney originating from muscle cells. They are usually found by an autopsy, whether the patient is asymptomatic or has symptoms (i.e., abdominal/flank pain, hematuria, palpable mass). Today the widespread use of ultrasonography and computed tomography has increased the detection of clinically asymptomatic renal leiomyomas. The differential diagnosis between leiomyomas and other malignant lesions (above all renal cell carcinoma or leiomyosarcoma) is still possible by histological examination. Radiological examinations are not sufficient for the differential diagnosis. Renal leiomyomas have no aggressive behaviour and they usually do not metastasize. The prognosis, after surgery, is excellent without recurrence. We report a case of leiomyoma in a 31-year-old man who presented hematuria and flank pain. We also review the literature and provide a summary of clinical, radiological and histological features of renal leiomyomas.

\section{Introduction}

Renal leiomyomas are rare benign tumours of the kidney originating from muscle cells. Differential diagnosis between leyomiomas and other malignant lesions is not possible with imaging, but only with histopathological exam. We report a case of leiomyoma in a 31-year-old man who presented hematuria and flank pain. We also review the literature and provide a summary of clinical, radiological and histological features of renal leiomyomas.

\section{Clinical history}

A 31-year-old male presented in the emergency department with hematemesis and abdominal pain on the left flank. An esophagogastroscopy was performed which revealed linear erosions as "grade B erosive esophagitis" that was treated with injection of adrenaline. The next day the patient presented a second time with left flank pain and hematuria.

\section{Methods}

The ultrasonography detected an enlargement of the left kidney with a mass occupying the caudal half of the organ, hypoechoic with irregular central fluid collection and destructuration of the normal renal echostructure. Using a power Doppler, we found that the lesion was hypovascular with no visualization of the renal vein.

A computed tomography (CT) scan the lesion was described as a voluminous heterogeneous mass of $8.6 \times 11 \mathrm{~cm}$ in the lower pole of the left kidney. Without contrast medium, the lesion appeared hyperdense compared the surrounding renal parenchyma and with signs of bleeding. After contrast medium injection, the tumour was hypodense in relation to the renal cortex. A CT scan also revealed a renal pelvis and ureter dilatation with non-flow of contrast medium into bladder (Fig. 1, Fig. 2). Since a definitive diagnosis was impossible, the patient underwent nephrectomy with adrenal gland-sparing and para-aortic and retroaortic lymphadenectomy.

\section{Results}

On gross examination, the mass was circumscribed and encapsulated with a well-defined limit between the thin rim of renal tissue and the lesion. The outer surface was lobular, and the cut surface showed a solid whorled white appearance. The tumour was very hard in consistency. No cystic change, hemorrhage, or necrosis was evident (Fig. 3).

At microscopic examination, the lesion showed fascicles of long spindle cells showing a whirling pattern with intervening areas of collagen deposition. Nuclei were regular oval with bland chromatin. Mitoses were not evident. No tumour cell pleomorphism, epithelial components or 


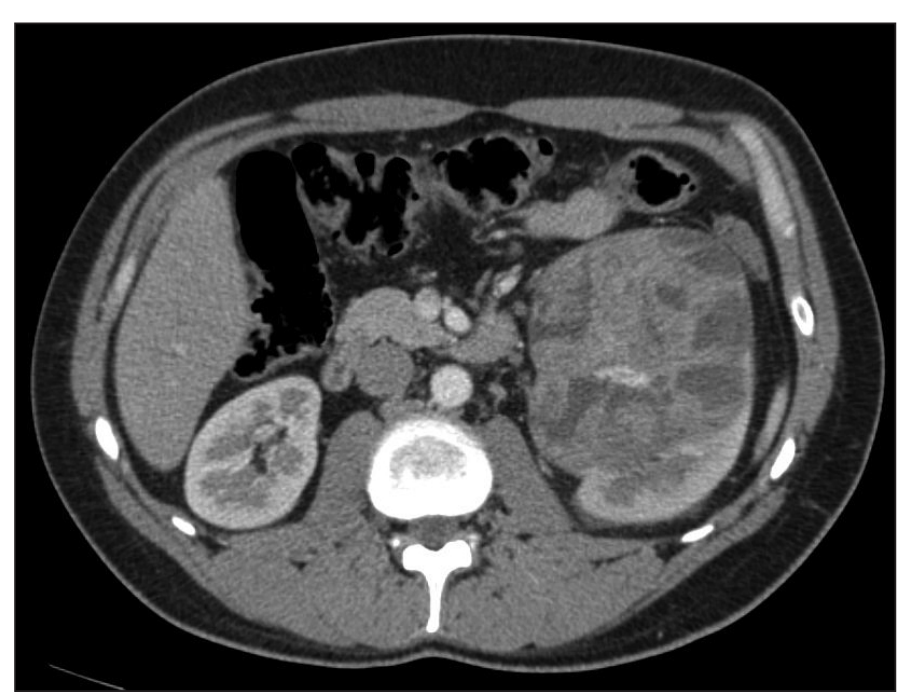

Fig. 1. Contrast enhanced axial computed tomography of the abdomen shows a large, poorly enhancing lesion involving the lower half of the left kidney. The mass is mainly hypodense and few foci of enhancement are present within the lesion.

immature elements were evident in the multiple sections. An initial diagnosis of renal fibroma was considered. An immunohistochemical evaluation revealed that tumour cells were strongly positive for smooth muscle actin and negative for cytokeratin and HMB 45 (Fig. 4). One year later an abdominal and chest CT scan was performed; there were no signs of local recurrence and metastases.

\section{Discussion}

Leiomyomas are rare, benign, mesenchymal tissue tumours originating from smooth muscle cells. They were described first time by Virchow in 1854. ${ }^{1}$ Leiomyomas are more common in the uterus. Although leiomyomas may involve any organ of the genitourinary tract, they most commonly affect the kidney. ${ }^{2}$ Leiomyomas originate from smooth muscle cells of renal capsule, pelvis, calices and blood vessels. ${ }^{3}$

Renal leiomyiomas may be triggered by a genetic predisposition followed by an acquired insult. ${ }^{4}$ Carpenter and colleagues demonstrated breakpoints in the q13-15 region of chromosome 12 in leiomyomas and congenital mesoblastic nephroma. ${ }^{5}$ Tsujimura and colleagues suggested an association between tuberous sclerosis and renal leiomyomas. ${ }^{6}$ Moreover, Krishnan and colleagues showed that EpsteinBarr virus infection could also lead to renal leiomyomas in immunocompromised patients. ${ }^{7}$

Renal leiomyoma is a rare benign tumour with autoptic evidence of $4.2 \%$ to $5.2 \% .{ }^{8}$ In a recent review developed by the J. B. Brady Urological Institute (Baltimore Maryland), in a period over 10 years on 1030 nephrectomies performed, renal leiomyomas represented $1.5 \%$ of benign renal tumours and $0.3 \%$ of overall tumours treated. ${ }^{9,10}$ Leiomyomas are often detected incidentally. The cases reported in the lit-

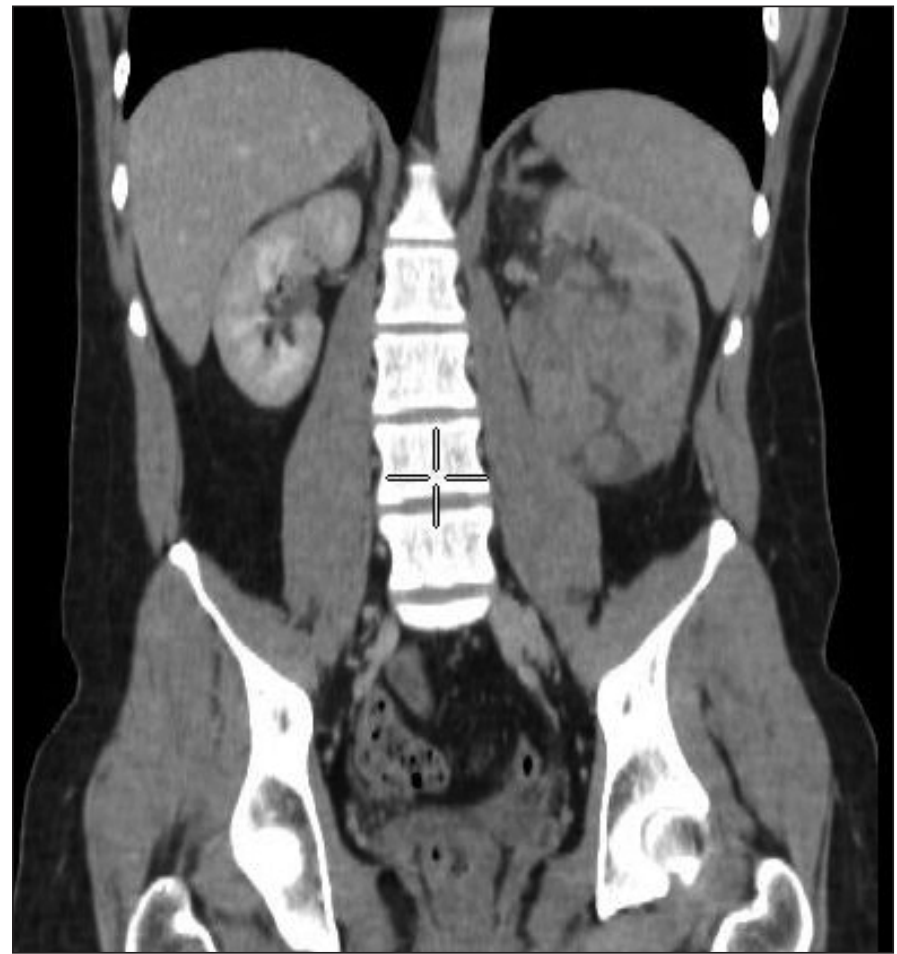

Fig. 2. The coronal reconstruction shows a large mass that disrupts the morphology of the left kidney.

erature suggest that these tumours affect adult women most frequently. The average age of presentation is 42 years. More than half of the cases present pain and a palpable mass and $20 \%$ present hematuria. ${ }^{8}$

Steiner and colleagues divided renal leiomyomas into two groups on the basis of the clinical features: (1) small tumours, asymptomatic, sometimes multifocal, incidentally detected in autopsy or after radical nephrectomy and (2) big tumours, often singular lesion, clinically manifested by symptoms/ signs as pain or abdominal palpable mass. However, during last 15 years, the widespread use of ultrasonography and

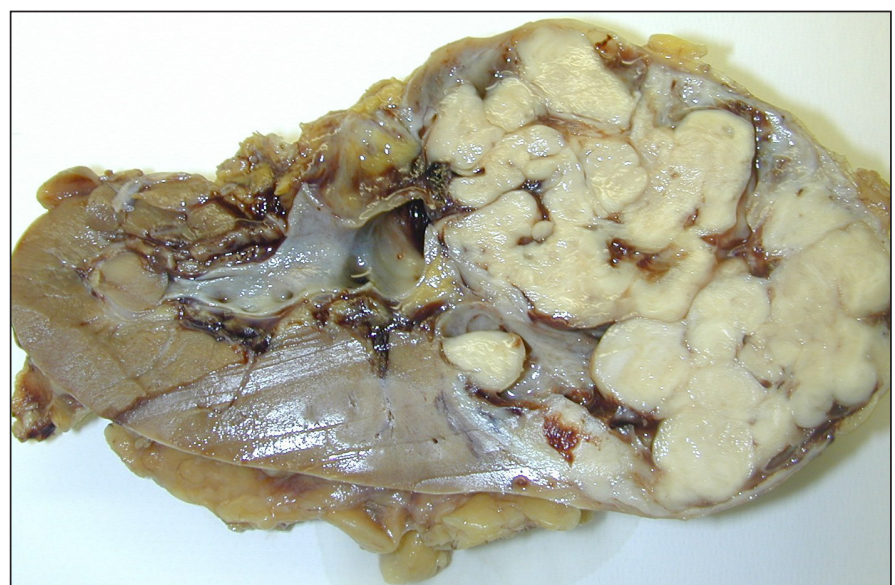

Fig. 3. Section of left kidney: the lesion is well circumscribed and encapsulated. 


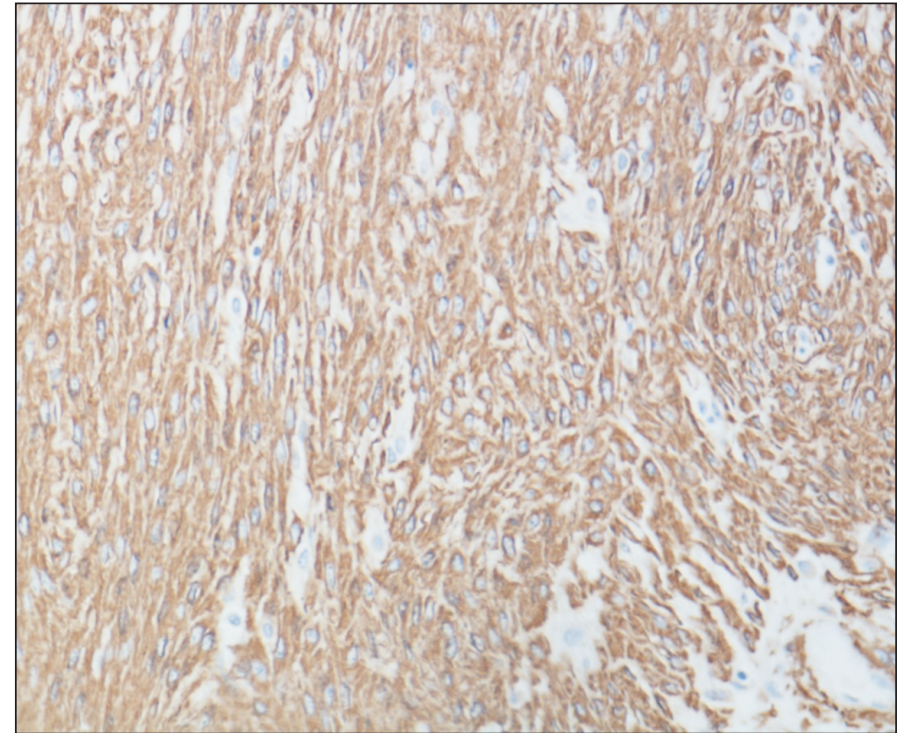

Fig. 4a. Histological aspect: IIC Smooth muscle actin 20x.

CT has increased the detection of clinically asymptomatic renal leiomyomas. In 1997, Wagner and colleagues added a third group to this classification: composition of tumours large enough to be detected radiographically, but without clinical signs and symptoms. ${ }^{11}$

In the first group of tumours, the average size is smaller than $5 \mathrm{~mm},{ }^{11}$ while "symptomatic" leiomyomas have an average width of $12.3 \mathrm{~cm}$ and an average weight of $1.84 \mathrm{~kg}{ }^{8}$ As of today, the biggest renal leiomyoma is $57.5 \mathrm{~cm}$ with a weight of $37.2 \mathrm{~kg} .{ }^{12}$

Macroscopically the renal leiomyoma is described as a white or red peripheral lesion, well-defined, with a solid aspect and elastic consistence. Colour is related to the mass vascularization. ${ }^{13}$

According to Steiner and colleagues, among symptomatic leiomyomas, tumour localization is subcapsular in 53\%, capsular in $37 \%$ and of renal pelvis in last $10 \% .{ }^{8}$ In addition, lesions larger than $12 \mathrm{~cm}$ may have cystic degeneration and hemorrhagic areas in $17 \%$ and $27 \%$ of cases, respectively. The cystic degeneration is not necessarily associated with sarcomatoid degeneration. ${ }^{14}$

Histologically, renal leiomyomas appear to be made of fusocellular elements showing the absence of mitotic figures, pleomorphism, hypercromatism and, above all, the absence of perilesional invasivity. The presence of these conditions is characteristic of leiomyosarcoma. ${ }^{15,16}$

The main differential diagnosis is usually made with angiomyolipoma of the kidney (AML). AML is a benign mesenchimal tumour composed of a variable proportion of adipose tissue, spindle and epithelioid smooth muscle cells and abnormal ticked-walled blood vessels. Most AMLs are composed of a variable mixture of mature fat, thickwalled blood vessels and smooth muscle, but there are times when only a smooth component is the most represented.

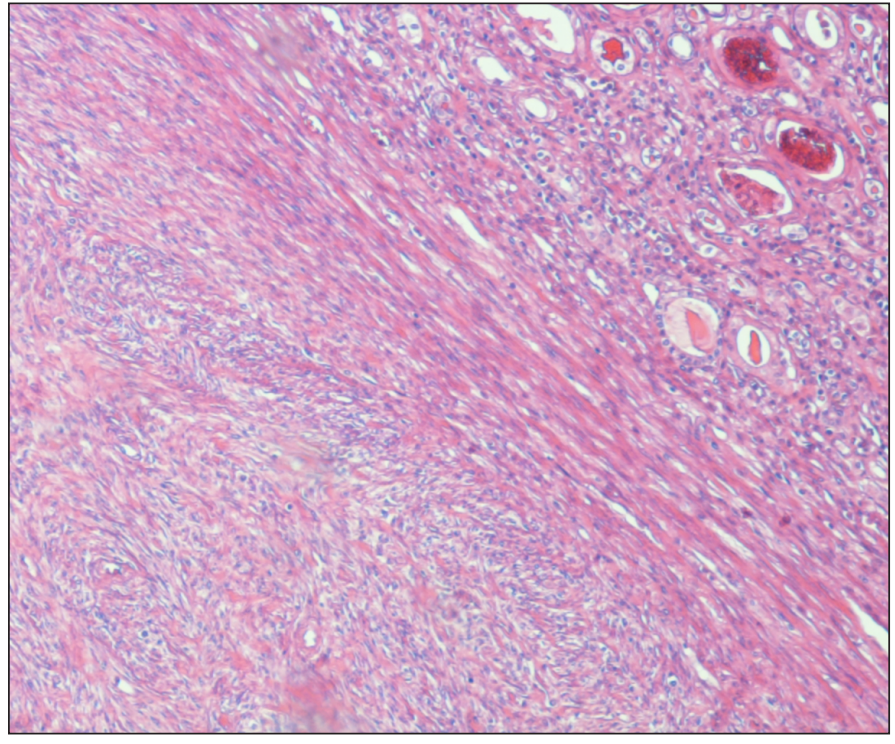

Fig. 4b. Histological aspect: Leiomyoma and normal kidney hematoxylin and eosin stain, $10 \times$.

AMLs are characterized by a co-expression of melanocytic marker (HMB45) and smooth muscle markers. Bonsin and colleagues showed a focally expression of HMB 45 in cortical leiomyomas and suggested a relationship to AMLs and other tumours of the perivascular epithelioid cell family. ${ }^{17}$

Currently, the differential diagnosis between leiomyoma and leiomyosarcoma is only histopathological after nephrectomy because the radiological aspect is not diriment in the diagnosis. Ultrasonographic evaluation detects leiomyoma as an hypoechoic lesion that could appear solid or cystic.

Derchi and colleagues described some CT scan features helpful for the differential diagnosis. The first feature is density. All leiomyomas examined before contrast were hyperdense compared to the kidney, with density similar to muscles. After contrast medium injection, the lesions had a lower enhancement than surrounding renal parenchyma. The second and final feature is localization and margins. Usually, these lesions have a peripheral location with welldefined margins, with no signs of infiltration into surrounding tissues ${ }^{18}$ In a patient with these radiological features, leiomyoma is part of the differential diagnosis, but does not rule out malignant diseases.

In these cases, surgery is still the gold standard. In suspicious cases, radical nephrectomy is the typical approach with an excellent prognosis. ${ }^{8}$ In cases of small lesions $(\leq 4 \mathrm{~cm})$, it is possible opt for conservative surgery. A further option for smaller lesions is renal biopsy, although this solution is still controversial.

\section{Conclusion}

Renal leiomyomas are benign and their behaviour is not aggressive. They do not metastasize. The prognosis, after sur- 
Brunocilla et al.

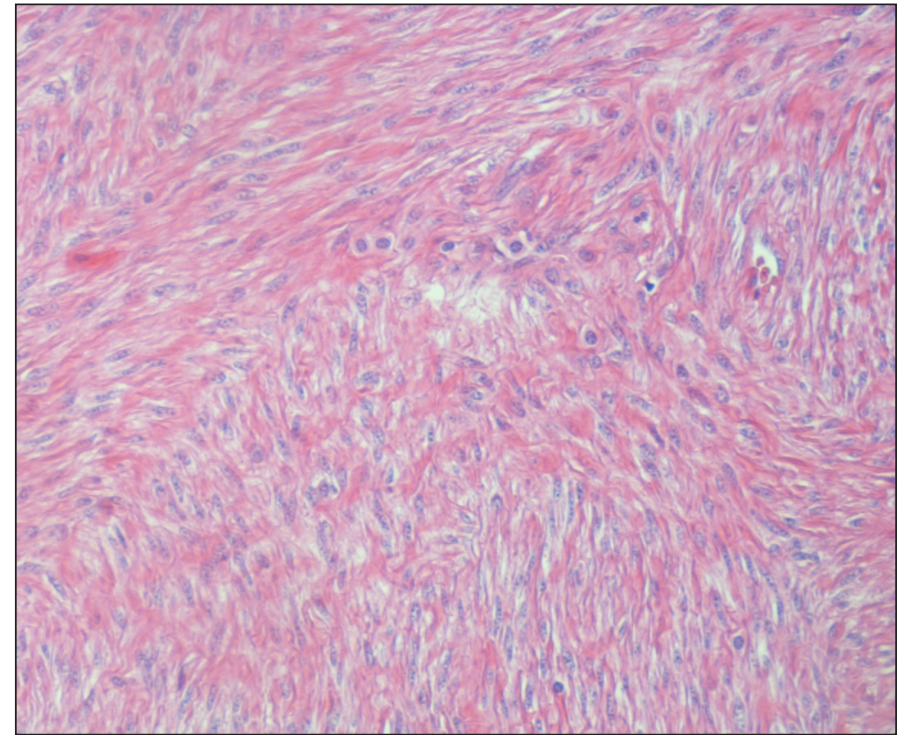

Fig. 4c. Histological aspect: Leiomyoma spindel cell hematoxylin and eosin $20 x$.

gery, is excellent without recurrence. This case reflects the clinical and radiological features described in the literature. It further illustrates how difficult it is to distinguish clinically a leiomyoma from other malignant lesions. The differential diagnosis is still possible by histological examination.

Competing interests: None declared.

This paper has been peer-reviewed.

\section{References}

1. Virchow R. Ueber Makroglossie und pathologische Neubildung quergestreifter Muskelfasern. Virchows Arch (Pathol Anat) 1854;7:126-38. http://dx.doi.org/10.1007/BF01936233

2. Yusim IE, Neulander EZ, Eidelberg I, et al. Leiomyoma of the genitourinary tract. Scan I Urol 2001;35:2959. http://dx.doi.org/10.1080/003655901750425873

3. Nagar AM, Raut AA, Narlawar RS, et al. Giant renal capsular leiomyoma: study of two cases. Br J Radiol 2004;77:957-8. http://dx.doi.org/10.1259/bir/13222406

4. Shum CF, Yip SK, Tan PH. Symptomatic renal leiomyoma: report of two cases. Pathology 2006;38:454-6. http://dx.doi.org/10.1080/00313020600922447

5. Carpenter PM, Mascarello JT, Krous HF, et al. Congenital mesoblastic nephroma: cytogenetic comparison to leiomyoma. Pediatr Pathol 1993;13:435-41. http://dx.doi.org/10.3109/15513819309048233

6. Tsujimura A, Miki T, Sugao H, et al. Renal leiomyoma associated with tuberous sclerosis. Urol Int 1996;57:192-3. http://dx.doi.org/10.1159/000282910

7. Krishnan R, Freeman JA, Creager AJ. Epstein-Barr virus inducued renal leiomyoma. J Urol 1999;161:212. http://dx.doi.org/10.1016/S0022-5347(01)62101-3

8. Steiner MS, Quinlan D, Goldman SM, et al. Leiomyoma of the kidney: presentation of 4 new cases and the role of computerized tomography. J Urol 1990;143:994-8.

9. Andreoiu M, Drachenberg D, MacMahon R. Giant renal leiomyoma: a case report and brief review of the literature. Can Urol Assoc J 2009:3:e58-e60.

10. Romero F, Kohanim S, Guilherme L, et al. Leiomyomas of the kidney: emphasis on conservative diagnosis and treatment. Urology 2005;66:1319. http://dx.doi.org/10.1016/i.urology.2005.06.078

11. Wagner BJ, Wong-You-Cheong JJ, Davis CJ Jr. Adult Renal Hamartomas. RadioGraphics 1997;17:155-69.

12. Clinton-Thomas CL. A giant leiomyoma of the kidney. Br I Surg 1956;43:497-501. http://dx.doi. org/10.1002/bjs. 18004318108

13. Alvarez Maestro M, Martiìnez-Pineiro L, Domínguez Franio P, et al. Leiomioma de la càpsula renal: presentacien de un caso y revisiòn de la literatura. Actas Urol Esp 2010;4:116-8.

14. Takezaki T, Nakama M, Ogawa A. Renal leiomyoma with extensive cystic degeneration. Urology 1985;25:401-3. http://dx.doi.org/10.1016/0090-4295(85)90500-X

15. Gordon MP Jr, Kimmelstiel P, Cabell CL. Leiomyoma of the kidney. J Urol 1939;42:507.

16. Bennington JL, Beckwith JB. Tumors of the kidney, renal pelvis, and ureter. Washington DC: Armed Forces Institute of Pathology, 2nd series; 1975; fasc. 12:215.

17. Bonsin SM. HMB-45 reactivity in renal leiomyomas and leiomyosarcomas. Mod Pathol 1996;9:664-9.

18. Derchi LE, Grenier N, Heinz-Peer G, et al. Imaging of renal leiomyomas. Acta Radiol 2008;49:833-8. http://dx.doi.org/10.1080/02841850802087228

Correspondence: Dr. Cristian Vincenzo Pultrone, Department of Urology, University of Bologna, S. Orsola-Malpighi Hospital, Via Palagi 9, 40134 Bologna, Italy; cristian28@libero.it 